\title{
Increased expression of MMP-9 and IL-8 are correlated with poor prognosis of Bladder Cancer
}

\author{
Sabrina Thalita Reis ${ }^{1,2}$, Katia Ramos M Leite ${ }^{1}$, Luís Felipe Piovesan², José Pontes-Junior ${ }^{1,2}$, Nayara Izabel Viana', \\ Daniel Kanda Abe ${ }^{1,2}$, Alexandre Crippa ${ }^{2}$, Caio Martins Moura' ${ }^{1}$, Sanarelly Pires Adonias' ${ }^{2}$, Miguel Srougi ${ }^{1,2}$ \\ and Marcos Francisco Dall'Oglio ${ }^{1,2^{*}}$
}

\begin{abstract}
Background: Extracellular matrix homeostasis is strictly maintained by a coordinated balance between the expression of metalloproteinases (MMPs) and their inhibitors. The purpose of this study was to investigate whether the expression of MMP-9, MMP-2 and its specific inhibitors, are expressed in a reproducible, specific pattern and if the profiles are related to prognosis in Bladder Cancer (BC).

Methods: MMP-9, MMP-2 and its specific inhibitors expression levels were analyzed by quantitative real-time polymerase chain reaction (qRT-PCR) in fresh-frozen malignant tissue collected from 40 patients with BC submitted to transurethral resection of bladder. The control group consisted of normal bladder tissue from five patients who had undergone retropubic prostatectomy to treat benign prostatic hyperplasia.

Results: MMP-9 was overexpressed in $59.0 \%$ of patients, and MMP-2, TIMP-1, TIMP-2, MMP-14, RECK and IL-8 was underexpressed in most of the patients. Regarding prognostic parameters we observed that high-grade tumors exhibited significantly higher levels of MMP-9 and IL-8 $(p=0.012, p=0.003)$. Invasive tumors ( $p$ T1-pT2) had higher expression levels of MMP-9 than superficial tumors $(p T a)(p=0.026)$. The same was noted for IL-8 that was more expressed by invasive tumors $(p=0.015, p=0.048)$. Most importantly tumor recurrence was related with higher levels of both MMP-9 $(p=0.003)$ and IL-8 $(p=0.005)$.

Conclusion: We have demonstrated that the overexpression of MMP-9 and higher expression of IL-8 are related to unfavorable prognostic factors of urothelial bladder cancer and tumor recurrence and may be useful in the follow up of the patients.
\end{abstract}

Keywords: Bladder cancer, Matrix metalloproteinase, Prognosis, Diagnosis, Gene expression

\section{Background}

Bladder cancer $(\mathrm{BC})$ is the second most common malignancy of the urinary tract. Approximately 383,300 new cases are estimated for 2011 world-wide [1]. Ninety percent of $\mathrm{BC}$ are urothelial carcinomas, previously named transitional cell carcinomas, and the majority are papillary low-grade, non-muscle invasive that recur in up to $80 \%$ of cases but rarely progress to muscle invasion [2]. In contrast, 10 to $20 \%$ of tumors are muscle invasive at diagnosis, and $50 \%$ of patients die from metastatic disease [3]. The molecular pathways of $\mathrm{BC}$ have been

\footnotetext{
* Correspondence: urologiamfd@uol.com.br

'Laboratory of Medical Investigation (LIM55), Urology Department, University of Sao Paulo Medical School, Sao Paulo, Brazil

${ }^{2}$ Uro-Oncology Group, Urology Department, University of Sao Paulo Medical School and Institute of Cancer of State of Sao Paulo (ICESP), Sao Paulo, Brazil
}

investigated to identify new potential markers for diagnosis, disease monitoring, prognosis and development of new targeted therapies [2,3].

Degradation of basal membranes and the extracellular matrix (ECM) is essential for tumor invasion and development of metastases, and matrix metalloproteinases (MMPs) are potent proteolytic enzymes that are known to play a key role in these processes. Within the MMP family, Matrix Metalloproteinase 2 (MMP-2) (gelatinase A, $72 \mathrm{kDa}$ ) and Matrix Metalloproteinase 9 (MMP-9) (gelatinase $\mathrm{B}, 92 \mathrm{kDa}$ ) cleave type IV collagen and gelatin, which are the main structural components of the basal membrane [4]. At the post-translational level, all MMPs are under control of specific tissue inhibitors (TIMPs). TIMP-1 specifically inhibits MMP-9 and TIMP-2 
inhibits MMP-2, moreover, it has been reported that Reversion-inducing cysteine-rich protein with Kazal motifs (RECK) inhibits both MMP2 and MMP-9. Considering stimulation, membrane type-1 MMP (MT1-MMP), also known as MMP14 is one of main activators, and also Interleukin-8 (IL-8) upregulates MMP2 and MMP9 in tumor cells, which is thought to be responsible for its angiogenic activity. The balance between secreted MMPs and their specific regulators plays an important role in maintaining connective tissue homeostasis in normal tissue [5].

In neoplastic diseases, an imbalance between MMPs and their regulators, leading to an excess of degradative activity, is assumed to be linked to the invasive character of tumor cells [6,7]. Expression of MMP-9 and MMP-2 has been implicated in the development and progression of many neoplasias, such as prostate [8], colorectal [9] and lung cancer [10].

The aim of the present study was to investigate whether MMP-9 e MMP-2 and its specific inhibitors, TIMP-1 and TIMP-2, MMP-14, IL-8 and RECK, are expressed in a reproducible, specific pattern in BC. Additionally, we evaluated the correlation between the expression of these genes and three important prognostic parameters, histological grade, pathological stage and angiolymphatic invasion. Also we analyzed the profile of MMPs and inhibitors with tumor recurrence.

\section{Patients and Methods \\ Patients}

The study was conducted using surgical specimens from 40 patients with $\mathrm{BC}$ who underwent transurethral resection in our institution between 2006 and 2008. The demographic, clinical and pathological data are described in Table 1. As control, we used normal bladder tissue from five male patients who had undergone retropubic prostatectomy to treat benign prostatic hyperplasia; the mean age of the control group was 64.0 years old, ranging from 60 to 70 . These cases were randomly selected from our database. All subjects provided informed consent to participate in the study and to allow their biological samples to be genetically analyzed. Approval for the study was given by the Institutional Board of Ethics (no. 0105/09).

\section{RNA Isolation and cDNA Synthesis}

All tumor samples were obtained from surgical specimens and immediately frozen at $-170{ }^{\circ} \mathrm{C}$ in liquid nitrogen. A slide with a mirror of the frozen fragment was stained with hematoxylin and eosin to verify that the tumor represented at least $75 \%$ of the fragment in patients with cancer and to demonstrate the absence of tumor in those without.
Table 1 Demographic characteristics of $\mathbf{4 0}$ patients with Bladder Cancer

\begin{tabular}{|c|c|}
\hline & Cases \\
\hline \multicolumn{2}{|l|}{ Age (years) } \\
\hline Mean & 69.0 \\
\hline Min - Max & $(47-87)$ \\
\hline \multicolumn{2}{|l|}{ Gender } \\
\hline Man n (\%) & $31(71.5)$ \\
\hline Woman n (\%) & $9(22.5)$ \\
\hline \multicolumn{2}{|l|}{ Grade } \\
\hline Low n (\%) & $18(45.0)$ \\
\hline High n (\%) & $22(55.0)$ \\
\hline \multicolumn{2}{|l|}{ Stage } \\
\hline pTa n (\%) & $19(47.5)$ \\
\hline pT1 n (\%) & $13(32.5)$ \\
\hline pT2 n (\%) & $8(20.0)$ \\
\hline \multicolumn{2}{|c|}{ Angiolinfatic invasion } \\
\hline Without n (\%) & $36(90.0)$ \\
\hline With n (\%) & $4(10.0)$ \\
\hline \multicolumn{2}{|l|}{ Recurrence } \\
\hline Without n (\%) & $21(67.7 \%)$ \\
\hline With n (\%) & $10(32.3 \%)$ \\
\hline
\end{tabular}

Total RNA was isolated with an RNAaqueous Kit (Applied Biosystems, CA, USA) according to the manufacturer's instructions. RNA concentration was determined by $260 / 280 \mathrm{nM}$ absorbance using a Nanodrop ND1000 spectrophotometer (Thermo Scientific). cDNA was generated using a High Capacity cDNA Reverse Transcription Kit (Applied Biosystems, CA, USA). The reactions were incubated at $25^{\circ} \mathrm{C}$ for $10 \mathrm{~min}$, followed by $37^{\circ}$ $\mathrm{C}$ for $120 \mathrm{~min}$ and $85^{\circ} \mathrm{C}$ for $5 \mathrm{~min}$. The cDNA was stored at $-20{ }^{\circ} \mathrm{C}$ until further use.

\section{Quantitative Real-Time PCR and Gene Expression}

Expression levels of the genes were analyzed by qRTPCR using an ABI 7500 Fast Real-Time PCR System (Applied Biosystems). Target sequences were amplified in a $10-\mu \mathrm{l}$ reaction containing $5 \mu \mathrm{l}$ of TaqMan Universal PCR Master Mix, $0.5 \mu \mathrm{l}$ of TaqMan Gene Expression Assays (primers and probes; see Table 2), $1 \mu \mathrm{l}$ of cDNA and $3.5 \mu \mathrm{l}$ of DNase-free water. The PCR cycling conditions were 2 minutes at $50{ }^{\circ} \mathrm{C}, 10$ minutes at $95{ }^{\circ} \mathrm{C}$, and then 40 cycles of 15 seconds at $95^{\circ} \mathrm{C}$ and $1 \mathrm{~min}$ at $60^{\circ}$ C. A TaqMan B2M assay was utilized as the endogenous control (Table 2).

We used the $\Delta \Delta \mathrm{CT}$ method to calculate the relative expression of the target genes using the formula $\Delta \Delta \mathrm{CT}=$ (CT target gene, BC sample - CT endogenous control, BC sample) - (CT target gene, normal bladder tissue sample - CT endogenous control, normal bladder tissue 
Table 2 Primers utilized

\begin{tabular}{lc}
\hline Gene & Assay \\
\hline MMP2 & Hs00234422_m1 \\
\hline MMP9 & Hs00957562_m1 \\
\hline TIMP1 & Hs00212624_m1 \\
\hline TIMP2 & Hs00234278_m1 \\
\hline MMP14 & Hs00237119_m1 \\
\hline RECK & Hs01019179_m1 \\
\hline IL8 & HS99999034_m1 \\
\hline B2M & Hs99999907_m1 \\
\hline
\end{tabular}

sample sample). The fold change in gene expression was calculated as $2^{-\triangle \Delta C T}$.

\section{Statistical analysis}

Qualitative variables were expressed as numbers and percentages. For analysis of expression according to pathological stage, grade, angiolymphatic invasion and recurrence, we used the $\mathrm{T}$ test for homogeneous variables or Mann-Whitney test for heterogeneous variables. Statistical analysis was performed using SPSS 19.0 for Windows, and significance was set at $\mathrm{p} \leq 0.05$.

\section{Results}

MMP-9 was overexpressed in $59.0 \%$ of patients (Figure 1). High-grade tumors exhibited significantly higher MMP-9 levels compared to low grade tumors $(p=0.012)$. The same was found for invasive tumors (pT1-pT2) that showed higher expression levels than superficial tumors $(p=0.026)$ (Table 3). Regarding tumor recurrence, we observed that patients with tumor recurrence showed higher expression of MMP-9 and IL-8 when compared with patients that not recurred ( $\mathrm{p}=0.003 ; \mathrm{p}=0.005$ ) (Table 4 ). We did not find differences in gene expression related to angiolymphatic invasion.

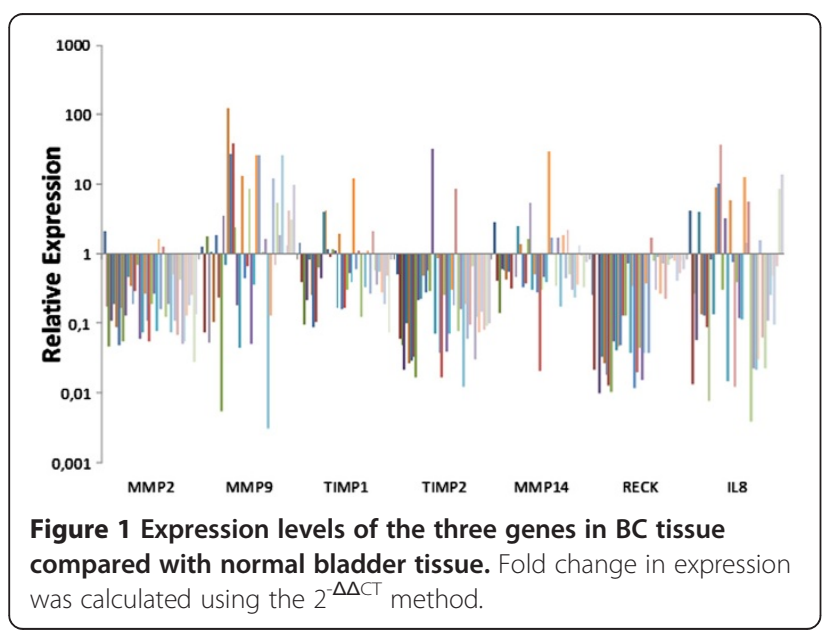

IL-8 was underexpressed in the majority of cases $(67.5 \%)$ compared with normal controls (figure 1). We also found correlation of IL-8 expression in relation to tumor grade. High grade tumors showed significantly higher levels of IL-8 ( $=0.003)$. The same was detected for pT1 and pT2 invasive tumors that showed higher expression of IL-8 when compared to noninvasive tumors $\mathrm{pTa}(\mathrm{p}=0.015, \mathrm{p}=0.048)$. Regarding tumor recurrence, patients who have recurred showed higher expression of IL-8 ( $\mathrm{p}=0.005)$. Again, there was no correlation between IL-8 expression and angiolymphatic invasion $(\mathrm{p}=0.161)$ (Table 3).

Almost all patients showed underexpression of MMP2, TIMP-1, TIMP-2, MMP-14 and RECK (92,5\%, $72.5 \%, 95.0 \%, 72.5 \%$ and $97.4 \%$ ) (Figure 1). We did not find significant differences between the expression of these genes with histological grade, pathological stage, angiolymphatic invasion (Table 3 ), or tumor recurrence (Table 4).

\section{Discussion}

The present study demonstrates that MMP-9 is overexpressed and TIMP-1 and RECK are underexpressed in malignant bladder tissues compared with normal bladder tissues. We demonstrated also that MMP-2 and its regulators (TIMP-2, MMP-14 and IL-8) are underexpressed in BC. Most importantly we found increased levels of MMP-9 and IL-8 in high grade, invasive and recurrent tumors.

Extensive studies have revealed that malignant invasion and metastasis require ECM degradation, mainly by MMPs [11]. Excessive or inappropriate expression of MMPs may contribute to the pathogenesis of cancer in a wide variety of cases by facilitating tissue degradation. Currently, there are more than 20 identified MMPs that can be categorized by substrate specificity. Despite the clinical significance of the pathogenetic impact of MMPs in human cancer, including BC, only a few studies of MMPs are available in the literature, and those mainly analyze protein expression [12].

In the present study, we have shown not only that MMP-9 is overexpressed in cancer tissue, but also that MMP-9 levels are significantly higher in patients with high grade and infiltrative tumors, two very important prognostics factors.

The same occurred considering IL- 8 expression, besides the fact that IL- 8 is underexpressed in cancer tissue, the relation between higher IL- 8 expression and unfavorable prognostic characteristics could be related to the fact that IL- 8 is important for tumor progression, but not for tumor initiation or promotion.

MMP-9 and IL-8 expression levels increased together with tumor invasiveness, suggesting that they are probably associated with a worse outcome in $\mathrm{BC}$. This is the 
Table 3 Relative expression of the genes in the malignant bladder tissue according to grade, Pathological stage and angiolinfatic invasion

\begin{tabular}{|c|c|c|c|c|c|c|c|c|c|c|}
\hline \multicolumn{4}{|c|}{ Grade Median (min-max) } & \multicolumn{4}{|c|}{ Pathological Stage Median (min-max) } & \multicolumn{3}{|c|}{ Angiolinfatic Invasion Median (min-max) } \\
\hline & & & $p$ & $\Gamma a(n=19)$ & & & $p$ & ut $(n=36)$ & & $p$ \\
\hline & & & & & & & & & & \\
\hline & ) & & & $0.687(0.00-38$ & $8.532(0.00$ & & & & & \\
\hline & & & & & & & & & & \\
\hline & & & 427 & 0 & & & 0.247 & & & 0.10 \\
\hline & & $-30.4)$ & 0.798 & $0.516(0.29-2.87)$ & $0.336(0.14-1.67)$ & $0.756(0.02-30.4)$ & 0.08 & & & 0.557 \\
\hline RECK & $0.175(0$. & $0.129(0.01-0.88)$ & 0.606 & $0.224(0.00$ & $0.046(0$. & $0.240(0$ & 0.953 & & & 0.77 \\
\hline IL8 & $0.075(0.00-37.2)$ & 0.783(0.01-13.63) & 0.003 & $0.087(0.00-37.2)$ & $0.750(0.02-13.6)$ & $2.042(0.01-12.9)$ & 0.015 & $0.132(0.00-37.2)$ & $2.412(0.30-5.85)$ & 0.161 \\
\hline
\end{tabular}

Fold change in gene expression was calculated using the $\Delta \Delta C \mathrm{CT}$ method (QRel $=2^{-\Delta \Delta C \mathrm{~T}}$ ).

first time that a study has shown a correlation between high grade, invasive tumors and IL- 8 mRNA expression in BC. Increased MMP-9 expression has also been shown to have an independent prognostic impact on operable non-small cell lung cancer [13] and renal cell carcinoma [14], and increased IL-8 expression has been associated with worse prognostic of colon cancer [15].

Another important finding of our study was the relationship between MMP-9 and IL-8 higher levels and tumor recurrence during a long follow-up period (mean of 40 months). The mean expression of MMP-9 and IL8 in patients with recurrence was greater than six times that observed in patients without recurrence. This result might reflect an important biological phenomenon that could be confirmed in larger studies and that could become a tool to identify patients likely to progress. MMPs are abundantly expressed in malignant tumors regardless of their origin, and a significant correlation between increased MMP expression and a poor prognosis in terms of survival has been demonstrated in several cases $[16,17]$. As a result, the possibility of MMPs being used as tumor markers has been suggested.

At the post-translational level, all MMPs are under the control of specific tissue inhibitors (TIMPs) that bind proximal to the catalytic domain of MMPs, preventing

Table 4 Relative expression of the genes in the malignant bladder tissue according to recurrence

\begin{tabular}{llcc}
\hline \multicolumn{4}{c}{ Recurrence Median (min-max) } \\
\hline Genes & without $(\mathrm{n}=21)$ & with $(\mathrm{n}=10)$ & $\mathrm{p}$ \\
\hline MMP2 & $0.106(0.04-1.23)$ & $0.223(0.05-0.67)$ & 0.529 \\
\hline MMP9 & $0.976(0.03-25.9)$ & $6.323(0.43-125.1)$ & $\mathbf{0 . 0 0 3}$ \\
\hline TIMP1 & $0.397(0.08-2.06)$ & $0.692(0.16-4.13)$ & 0.114 \\
\hline TIMP2 & $0.075(0.01-32.5)$ & $0.270(0.03-0.84)$ & 0.456 \\
\hline RECK & $0.516(0.02-5.31)$ & $0.419(0.28-1.62)$ & 0.390 \\
\hline IL8 & $0.288(0.01-1.65)$ & $0.090(0.01-0.81)$ & 0.681 \\
\hline Fol & $0.096(0.00-13.6)$ & $0.783(0.11-37.2)$ & $\mathbf{0 . 0 0 5}$
\end{tabular}

Fold change in gene expression was calculated using the $\triangle \Delta C T$ method (QRel $=2^{-\Delta \Delta C \mathrm{~T}}$ ). substrate attachment. TIMPs are not simply regulators of MMP activity; they also have multifunctional roles that include cell growth promotion and inhibition of angiogenesis [18]. Four TIMPs have been identified. They inhibit all MMPs, forming non-covalent complexes with the active forms. Among them, TIMP-1 selectively binds pro-MMP-9 and is considered the main inhibitor of MMP-9, TIMP-2 binds pro-MMP-2. The reversioninducing cysteine-rich protein with Kazal motifs (RECK) gene was identified as an inducer of a flat morphology in v-Ki ras-transformed NIH3T3 cells [19]. RECK expression is observed in normal human organs; however, several oncogenic factors, such as activated Ras [20], EBV latent membrane protein 1 [21], and HER-2/neu [22] suppress the expression of RECK. Additionally, it has been reported that RECK overexpression decreases the amount of active MMP-2 and MMP-9 in conditioned medium and inhibits metastatic activity in vitro [23] and in vivo [24]. Considering activation of MMPs, MT1MMP is a key enzyme in tumor angiogenesis and metastasis: it hydrolyzes a variety of ECM components, and is a physiological activator of pro-MMP-2 and MMP-9. IL8 is involved in the transcription induction of MMP-2 increasing stromal invasion by tumor cells facilitating angiogenesis and development of metastasis.

Interestingly, our results demonstrate that there is an upregulation of MMP-9 and a downregulation of its specific inhibitors, TIMP-1 and RECK, in BC. Otherwise, we demonstrated that the low expression of TIMP-2, MMP14 and IL- 8 may be responsible for the decreased MMP-2 expression in $\mathrm{BC}$ tissue.

\section{Conclusions}

In conclusion, this is the first study to indicate the prognostic relevance of MMP-9 and IL- 8 mRNA expression in $\mathrm{BC}$, as demonstrated by the significant correlation between its expression and invasive, high grade tumors and also $\mathrm{BC}$ recurrence. These findings suggest the possibility of using the profiles of MMP-9 and IL-8 as prognostic 
marker and, in the future, might inspire the development of targeted drugs.

\section{Abbreviations}

BPH: Benign prostatic hyperplasia; CDNA: Complementary deoxyribonucleic acid; ECM: Extracellular matrix; MMP: Matrix metalloproteinase; BC: Bladder Cancer; qRT-PCR: Quantitative real-time polymerase chain reaction; RECK: Reversion-inducing cysteine-rich protein with Kazal motif; RNA: Ribonucleic acid; TIMP-1: Tissue inhibitor of metalloproteinases; TIMP-2: Tissue inhibitor of metalloproteinases; IL-8: Interleukin 8.

\section{Competing interests}

The authors declare that they have no competing interests

\section{Acknowledgements}

This study was supported by FAPESP (Fundação de Amparo à Pesquisa do Estado de Sao Paulo) under protocol number 2009/50368-9, we acquired all necessary reagent with this support.

\section{Authors' contributions}

AC, JPJr, DKA-conception and design: -acquisition of patients and data. STR, KRL-Drafting of the manuscript. STR, NIV, CMM-molecular genetic studies, SPA- Administration support. STR- Statistical Analysis. MFD, AC, KRL-critical revision and important intellectual content MS-supervision. All authors read and approved the final manuscript.

Received: 23 January 2012 Accepted: 13 June 2012

Published: 13 June 2012

\section{References}

1. Jemal A, Bray F, Center MM: Global Cancer Statistics, 2011. Cancer J Clin. 2011, 61:69-90.

2. Jebar AH, Hurst CD, Tomlinson DC: FGFR3 and Ras gene mutationsare mutually exclusive genetic events in urothelial cell carcinoma. Oncogene 2005, 24:5218-5225.

3. Borden LS, Clark PE, Hall MC: Bladder Cancer. Curr Opin Oncol 2005, 17:275-280.

4. Toi M, Ishigaki S, Tominaga T: Metalloproteinases and tissue inhibitors of metalloproteinases. Breast Cancer Res Treat 1998, 52:113-124.

5. Henriet $P$, Blavier L, Declerck YA: Tissue inhibitors of metalloproteinases (TIMP) in invasion and proliferation. APMIS 1999, 107:111-119.

6. Nawrocki B, Polette M, Marchand V, Monteau M, Gillery P, Tournier JM: Expression of matrix metalloproteinases and their inhibitors in human bronchopulmonary carcinomas: quantificative and morphological analyses. Int J Cancer 1997, 72:556-564.

7. Wallard MJ, Pennington CJ, Veerakumarasivam A, Burtt G, Mills IG, Warren A, Leung HY, Murphy G, Edwards DR, Neal DE, Kelly JD: Comprehensive profiling and localisation of the matrix metalloproteinases in urothelial carcinoma. Br J Cancer 2006 Feb 27, 94:569-577.

8. Eissa S, Ali-Labib R, Swellam M, Bassiony M, Tash F, El-Zayat TM: Noninvasive diagnosis of bladder cancer by detection of matrix metalloproteinases (MMP-2 and MMP-9) and their inhibitor (TIMP-2) in urine. Eur Urol 2007, 52:1388-1396.

9. Liabakk NB, Talbot I, Smith RA, Wilkinson K, Ballewill F: Matrix metalloproteinase 2 (MMP-2) and matrix metalloproteinase 9 (MMP-9) type IV collagenase in colorectal cancer. Cancer Res 1996, 56:190-196.

10. Kodate M, Kasai T, Hashimoto H, Yabumoto K, Iwata Y, Manobe H: Expression of matrix metalloproteinase (gelatinase) in T1 adenocarcinoma of the lung. Pathol Int 1997, 47:461-469.

11. Luca M, Huang S, Gershenwald JE, Singh RK, Reich R, Bar-Eli M: Expression of interleukin- 8 by human melanoma cells up-regulates MMP-2 activity and increases tumor growth and metastasis. Am J Pathol 1997, 151:1105-1113.

12. Yuan JP, Li T, Chen HB, Li ZH, Yang GZ, Hu BY, Shi XD, Tong SQ, Li YX, Guo XK: Analysis of gene expression profile in gastric cancer cells stimulated with Helicobacter pylori isogenic strains. J Med Microbiol 2004, 53:965974.

13. Mian BM, Dinney CP, Bermejo CE, Sweeney P, Tellez C, Yang XD, Gudas JM, McConkey DJ, Bar-Eli M: Fully human anti-interleukin 8 antibody inhibits tumor growth in orthotopic bladder cancer xenografts via down-regulation of matrix metalloproteases and nuclear factor-kappaB. Clin Cancer Res 2003, 9:3167-3175.
14. Cho NH, Shim HS, Rha SY, Kang SH, Hong SH, Choi YD, Hong SJ, Cho SH: Increased expression of matrix metalloproteinase 9 correlates with poor prognostic variables in renal cell carcinoma. Eur Urol 2003, 44:560-566.

15. Nastase A, Pâslaru L, Niculescu AM, Ionescu M, Dumitrașcu T, Herlea V, Dima S, Gheorghe C, Lazar V, Popescu I: Prognostic and predictive potential molecular biomarkers in colon cancer. Chirurgia (Bucur). 2011, 106(2):177-185.

16. Takeuchi $T$, Hisanaga $M$, Nagao $M$, et al: The membrane-anchored matrix metalloproteinase (MMP) regulator RECK in combination with MMP-9 serves as an information prognostic indicator for colorectal cancer. Clin Cancer Res 2004, 10:5572-5579.

17. Heppner KJ, Matrisian LM, Jensen RA, Rodgers WH: Expression of most matrix metalloproteinase family members in breast cancer represents a tumor-induced host response. Am J Pathol 1996, 149:273-282.

18. Cox G, Jones JL, Walker RA, Steward WP, O'Byrne KJ: Angiogenesis and non-small cell lung cancer. Lung Cancer 2000, 27:81-100.

19. Takahashi C, Sheng Z, Horan TP, et al: Regulation of matrix metalloproteinase-9 and inhibition of tumor invasion by the membrane-anchored glycoprotein RECK. Proc Natl Acad Sci U S A 1998, 95:13221-13226.

20. Sasahara RM, Takahashi C, Noda M: Involvement of the Sp1 site in rasmediated down-regul ation of the RECK metastasis suppressor gene. Biochem Biophys Res Commun 1999, 264:668-675.

21. Chang HC, Liu LT, Hung WC: Involvement of histone deacetylation in ras-induced down regulation of metastasis suppressor RECK. Cell Signal 2004, 16:675-679.

22. Hsu MC, Chang HC, Hung WC: HER-2/neu represses the metastasis suppressorRECK via ERK and Sp transcription factor to promote cell invasion. J Biol Chem 2006, 281:4718-4725.

23. Oh J, Takahashi R, Kondo S, et al: The membrane anchored MMP inhibitor RECK is a key regulator of extracellular matrix integrity and angiogenesis. Cell 2001, 107:789-800.

24. Chang CK, Hung WC, Chang HC: The Kazal motifs of RECK protein inhibit MMP-9 secretion and activity and reduce metastasis of lung cancer cells in vitro and in vivo. J Cell Mol Med 2008 2008, 12:12. ahead of print.

\section{doi:10.1186/1471-2490-12-18}

Cite this article as: Reis et al.: Increased expression of MMP-9 and IL-8 are correlated with poor prognosis of Bladder Cancer. BMC Urology 2012 12:18.

\section{Submit your next manuscript to BioMed Central and take full advantage of:}

- Convenient online submission

- Thorough peer review

- No space constraints or color figure charges

- Immediate publication on acceptance

- Inclusion in PubMed, CAS, Scopus and Google Scholar

- Research which is freely available for redistribution 